\title{
Industrial upgrade and economic governance in the Pearl River Delta—a case study of Dongguan city
}

\author{
Zhifeng Wang ${ }^{*}$, Xiaoming Xu and Zhiqing Liang
}

\author{
* Correspondence: \\ wangzf@cufe.edu.cn \\ School of Management Science and \\ Engineering, Central University of \\ Finance and Economics, 39 South \\ College Road, Haidian District, \\ Beijing 100081, People's Republic of \\ China
}

\begin{abstract}
The Pearl River Delta, one of the main regions of China's export-oriented economy, has benefited from its traditional economic structure for three decades which in turn appeared to hinder further economic development recently. To advance industrial restructuring and upgrading, the governments have promulgated policies and appropriated special funds to optimize the industrial structure of the Pearl River Delta. Dongguan is a famous export-oriented and manufacturing city in China. Taking Dongguan city as a case, and applying the method of Difference-inDifference (DID), using time-series data from 1997 to 2014, this article analyzes the policy benefits of Dongguan's industrial transformation and upgrading, aiming to not only examine the effectiveness of industrial upgrades and the effects of economic governance in the Pearl River Delta but provide some reference to other export-oriented regions of China.
\end{abstract}

Keywords: Industrial upgrade, Economic governance, Industrial policy valuation

\section{Background}

Since the Reform and Opening up, China's coastal areas represented by the Pearl River Delta focused on manufacturing activities. In the implementation of exportoriented economic policies, many positive advances have been achieved, including the development and structure of the economy, the level of openness, and the degree of foreign trade in these regions, which are important engines of economic growth in China. However, the economic model of high manufacturing dependence resulted in the industry's low value-added, resource waste, and environmental pollution.

The economic structure of export-oriented regions has changed dramatically, both domestically and internationally. To meet the economic problems and challenges, the governments have promulgated policies and appropriated special funds to support the implementation of industrial restructuring and upgrading. The Guangdong provincial government made the strategy of "double transference" and a series of supporting industrial policies to promote industrial restructuring and implemented economic governance policies with industrial upgrading as the core. How did these governmentled industrial policies' effectiveness and whether the objective of optimizing industrial structure is achieved? These problems are a "hot topic" of current academic research.

(c) The Author(s). 2016 Open Access This article is distributed under the terms of the Creative Commons Attribution 4.0 International License (http://creativecommons.org/licenses/by/4.0/), which permits unrestricted use, distribution, and reproduction in any medium, provided you give appropriate credit to the original author(s) and the source, provide a link to the Creative Commons license, and indicate if changes were made. 
Dongguan city, known as the "world factory," which earlier faced the challenge of transforming economic governance and industry, is a typical representative of the Pearl River Delta. Research on Dongguan will help evaluate the effectiveness of industrial upgrading policy in the Pearl River Delta and will offer guidance to government policy making.

\section{Literature review}

Long-term dependence on an export-oriented economy and resource consumption makes industrial transformation imminent in the Pearl River Delta. In recent years, studies on industrial transformation and the evaluation of policy effectiveness in the Pearl River Delta and Dongguan have emerged and can be reviewed from the following aspects:

\section{Research on industrial transformation of the Pearl River Delta and Dongguan}

The existing research on the industrial transformation of the Pearl River Delta region can be divided into three levels: the first is the succession among three industries. For example, Zhao Lingling (2011) found that the proportion of the tertiary industry is gradually increasing, but the industrial structure distribution is not balanced in terms of each city. The second is the industrial restructuring inside the industry sector, such as an upgrade of manufacturing from the labor-intensive model to the technology-intensive one. $\mathrm{Wu}$ Hanxian (2011) explored the process of undertaking the labor-intensive manufacturing aspect of Zhanjiang city, Shanwei city, and Meizhou city, which are less-developed cities surrounding the Pearl River Delta region. Importantly, through the microlevel of enterprise industrial upgrading, Weigen and Ran (2010) researched the global value chain (GVC) model of three kinds of enterprises in the Pearl River Delta and their impact on industrial transformation and revealed the micro-mechanism of the transformation dilemma. Dongguan's economy is oriented towards and developed by the market where the "Bottom to Up" model creates the economic miracle of Dongguan. Faced with the domestic and international pressures, Wu Xiaofeng (2007) thought that it was necessary for Dongguan to design a "Top to Down" model to sustain its economic development. From the view of changes in the organizational form and ownership structure, Lai Wenfeng (2007) stated that Taiwan-funded enterprises focus on Processing Industries and Compensation Trade in Dongguan has been existed as unincorporated entities, which resulted in interest conflicts between local government and enterprises. A lower dependence on the original path is necessary for Dongguan to smoothly advance and upgrade industrial transformation. Qiu Weinian and Tang Xiuxian (2011) divided Dongguan's economic development process into four steps: initial stage, rapid development stage, promotion stage, and upgrade stage. Their research then explored various reasons for industrial transformation in Dongguan that gave careful consideration to the impact of complicated economic factors on the development path.

\section{Policy evaluation of industrial policy and government governance}

There are a number of branches of research on the evaluation of industrial policy within China and abroad. Melissa Liew and White (2007) studied how to use the Petri net model to empirically analyze industrial policy by using an algebraic method. 
Takatoshi Ito (1992) explored the role of industrial policy and structure in Japan and found that industrial policy can improve the production efficiency of manufacturing. Tybout (1992), through the empirical analysis of government policies, found that industrial policy is invalid and that governments' intervention will hinder industrial development. More recent research by Zhiyong and Xuemei (2014) used Pearl River Delta panel data of the treatment group, and Yangtze River Delta, the control group, to analyze the net effect of "Double Transformation" strategy in the Pearl River Delta. This research showed that industrial policy has, to a certain degree, hindered its development. They also found that opening up markets are conducive to the development of secondary industries but not to overall industrial upgrade. Kang Lingxiang (2014) studied the responses of local enterprises to various industrial restructuring policies using a comparative analysis method and described the effect of the current industrial transformation policy. Compared with enterprises' behavior without government intervention, the article explained the impact that government-led industrial transformation will bring on the enterprises.

All the abovementioned studies provide a basis for the research of upgraded industrial transformation and policy evaluation in the Pearl River Delta, especially in Dongguan. As a whole, this research is still in the initial stage. For example, the majority of the existing research is qualitative that is not deep enough to enable concrete recommendations, while the quantitative studies are inadequately short. In addition, the object in the existing industrial transformation research is relatively simple, limited to an economic region or a city, with the result being that the comparative research of two regions is relatively insufficient.

Through analyzing the evolution of industrial structure in Dongguan, this paper evaluates industrial policy, explores the economic structure and governance efficiency of the Pearl River Delta, and enriches the relevant research in the following areas: (1) makes a comprehensive analysis of the industrial transformation policy of Dongguan and its impact on the industrial structure of the region leading to a deeper understanding about the quality and quantity of the industry transformation; (2) uses the Difference-in-Difference (DID) model to quantitatively analyze the implementation effectiveness of the related industrial transformation policies in Dongguan that improves the existing research; and (3) contributes to further research in that most of the export-oriented regions of China are in a critical period of industrial upgrade, just like Dongguan.

\section{Methods}

\section{Impact of industrial upgrade policy on its industrial structure in Dongguan}

Many problems have emerged from the original industrial pattern due to today's complex global economic situation, which appeared to have hindered further development of Dongguan city. In 2006, responding positively to the call of the industrial transformation of Guangdong Province, Dongguan's municipal government implemented the doubletransformation of economy and society industry strategy. In the Government Work Report, Dongguan's municipal government underlined the adjustment and optimization of the economic structure, the utilization of high technology to drive the transformation of traditional industries, and the improvement of the competitiveness of traditional manufacturing, which guided a series of following supporting policies. The implementation of 
this industrial policy has brought significant impacts on Dongguan. Thus, Dongguan city has stepped into the stage of industrial transformation.

Dongguan has achieved a rapid increase of economic strength during the past three decades, from a single manufacturing-based industry structure to a diversified industry structure. In the early days of the reform and opening up, agriculture was Dongguan's premier industry. It also accounted for almost half of the proportion. With the capital input from the "Processing Industries and Compensation Trade" and the Joint-Venture enterprises, the manufacturing industry has developed rapidly while the primary industry declines year by year. We can see from Fig. 1 that the second industry accounted for approximately 57.3\% of GDP in Dongguan in 2006. Subsequently, as the industrial restructuring policies conducted, the proportion of the second industry began to decline, and in contrast, that of tertiary industry aggrandized gradually, exceeding the second industry's share of production in 2012 by a more-than-half ratio. Since then, tertiary is the pillar industry in Dongguan.

Dongguan accelerated its industrialization since the "Processing Industries and Compensation Trade" policy. This, however, has evoked great controversy in the process of economic development due to the resulting reduced taxes from low valueadded activities and unclear property rights caused by the absence of enterprises' independent legal entities. In order to advance industrial restructuring, Dongguan's municipal government encouraged transformation to the Joint-Venture enterprises. As can be seen from Fig. 2, both "Processing Industries and Compensation Trade" enterprises and foreign-funded enterprises showed a rising trend in the actual utilization of foreign investment before 2004. In 2005, the amount of foreign capital used by the latter decreased significantly, influenced by the macro-economic environment while that of the former was relatively unchanged. But since 2006, as a consequence of government promotion, utilization of foreign capital in Dongguan city has changed greatly. Figure 2 shows the upward trend in foreign direct investment, mainly due to the rapid increase of the latter's utilization of foreign capital despite the tremendous

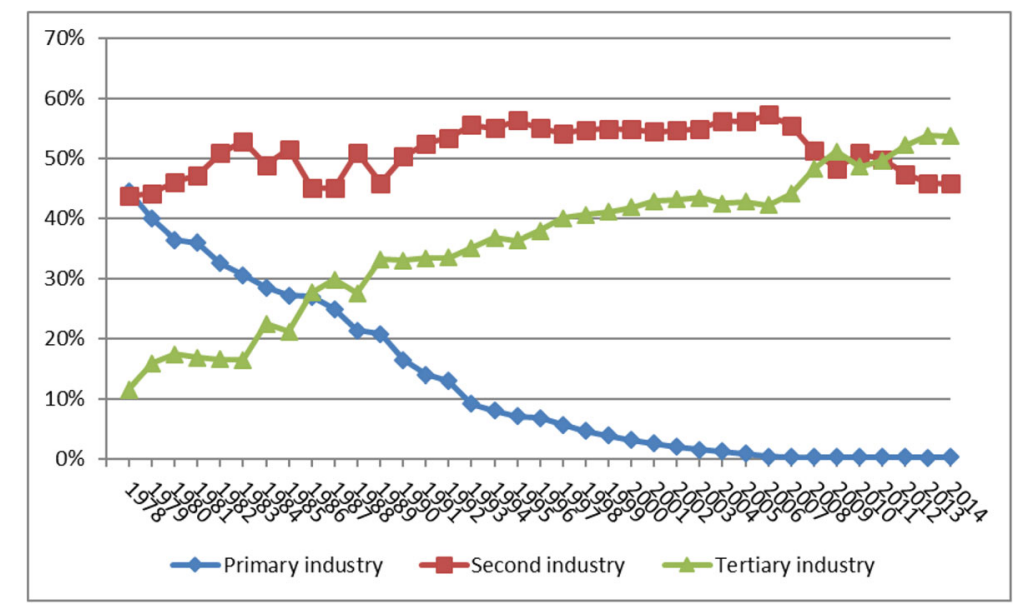

Fig. 1 Shares of three industries in GDP of Dongguan 1978-2013. Source: Dongguan Statistical Yearbook (2014) 


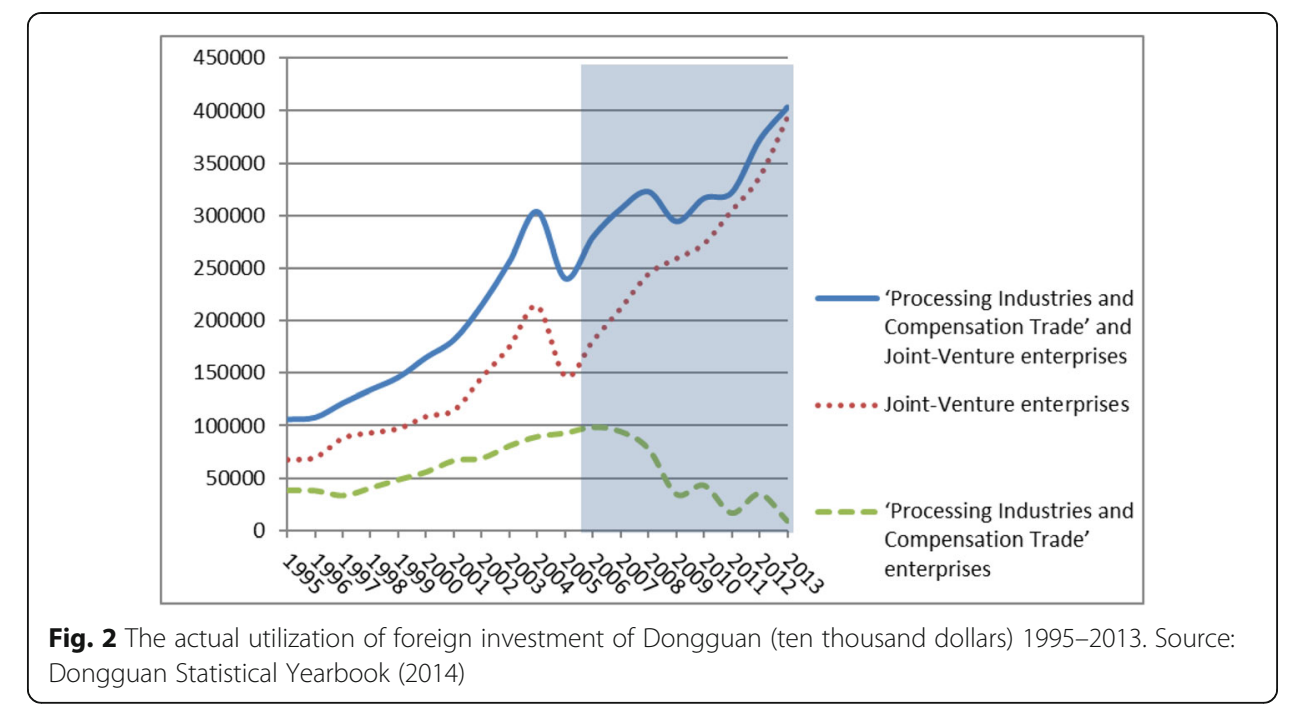

reduction of the processing industries and compensation trade. Therefore, processing industries and compensation trade have gradually been replaced by the Joint-Venture enterprises, which is the trend of the industrial transformation in Dongguan.

\section{Availability evaluation of the industrial upgrade policy of Dongguan}

Industrial upgrading and transformation inevitably brings economic benefit changes. This paper uses the DID model to analyze the effect of related industrial restructuring policies since 2006. We regress the data from 1997 to 2014, collecting from Guangdong Statistical Yearbook, to analyze the policy benefits of Dongguan's industrial transformation and upgrading. The primary goal of Dongguan's industrial transformation is to optimize the traditional manufacturing industry. Therefore, this paper mainly analyzes the change of the secondary industry.

Measures of variables and explanations of data are as follows: (1) This paper uses PCET (per capita tax of above Designed Size Enterprises), which reflects the economic benefits of the enterprises and their contributions to the tax, to measure the effectiveness of industrial upgrading. (2) We use the growth rate of GDP (GDP_R) to measure the level of economic development that can affect the direction of industrial upgrading. (3) Due to the obvious interaction between the secondary and the tertiary industries, we use the added value of tertiary industry (ThirdZ) as a control variable. (4) The amount of foreign direct investment (FDI), a control variable, measures the extent of the openness of a region, which is crucial to industrial upgrading. (5) Total social fixedasset investment has an influence on the manufacturability and productivity of the enterprises, considering its logarithm (LIFA) as a control variable.

\section{Results and Discussion}

\section{Direction model}

This paper uses the advance coefficient of industrial structure $\left(E_{2}\right)$ to measure the advanced degree of the secondary industry's growth with respect to overall economy's system. Our formula is as follows:

$$
E_{2}=\alpha_{2}+\left(\alpha_{2}-1\right) / R_{t}
$$




$$
R_{t}=\left(\ln \left(\mathrm{GDP}_{\text {Reporting period }}\right)-\ln \left(\mathrm{GDP}_{\text {Base period }}\right)\right) / n
$$

We use $\alpha_{2}$ to express the ratio of the secondary industry's share in the GDP (present value) of each reporting period and that of base period (1997), use $R_{t}$ to show the average growth rate of the economic system in the same period of secondary industry, and we use $n$ to represent the year number.

The year 2006 is the dividing line. The dummy variable, YEAR06, equals 0 from 1997 to 2005 and is 1 from 2006 to 2012 . The formula of the model is then:

$$
E_{2}=\beta_{0}+\beta_{1} \text { YEAR06 }+\beta_{2} \mathrm{GDP}_{R}+\beta_{3} \text { ThirdZ }+\beta_{4} \mathrm{FDI}+\beta_{5} \mathrm{LIFA}+\mu_{i}+\varepsilon_{i t}
$$

The regression results are shown in Table 1 . The significant level is relatively low, due to the small sample size, but we can still observe regularity.

The coefficient of YEAR06 is positive, being significant at the level of 5\%, which indicates that the secondary industry has developed at a relatively high speed since the policies of industrial transformation were promulgated.

The coefficient of GDP is negative and that of GDP_R is positive, being significant at the level of $1 \%$. These data indicate that the growth rate of GDP slows down with the present increase of GDP in Dongguan. The secondary industry has realized advanced development when GDP maintained rapid growth; the growth rate of GDP decreased, and at the meantime, the development of the secondary industry witnessed the relative sloth. ThirdZ is not significant at the level of $10 \%$, which indicates that there is not a large correlation between the growth of the third industry and the relative growth rate of the secondary industry. A possibility may be that the slowdown of the relative speed of development of the second industry is likely to be the inevitable result of GDP growth, rather than government policy.

The coefficient of FDI is positive and significant at the level of $10 \%$, which indicates that there is a positive correlation between foreign direct investment and the relative growth rate of the secondary industry. That is to say, opening up promotes the propulsion of industrial restructuring and upgrading. The coefficient of LIFA is positive, being significant at the level of $1 \%$, which indicates that the total investment in fixed assets caused the secondary industry to develop rapidly.

\begin{tabular}{|c|c|c|c|c|}
\hline \multirow[t]{2}{*}{ Variables } & \multicolumn{2}{|c|}{ Direction model } & \multicolumn{2}{|c|}{ Benefit model } \\
\hline & Coefficient & $P$ & Coefficient & $P$ \\
\hline Year06 & 0.4127789 & 0.014 & 7.021549 & 0.050 \\
\hline GDP & -0.0003815 & 0.002 & & \\
\hline GDP_R & 0.0391718 & 0.000 & -0.1042196 & 0.523 \\
\hline ThirdZ & $-6.79 E-08$ & 0.185 & & \\
\hline FDI & 0.00000213 & 0.075 & & \\
\hline LFDI & & & 16.03161 & 0.026 \\
\hline LIFA & 0.2318513 & 0.006 & -6.936575 & 0.070 \\
\hline _cons & -0.782132 & 0.041 & -141.1331 & 0.036 \\
\hline$R$-squared & 0.9663 & & 0.7736 & \\
\hline
\end{tabular}

Table 1 Regression results of direction model and benefits model 


\section{Benefit model}

It is the main goal for industrial transformation and upgrade to improve production, as well as management, profits, and taxes of the enterprise. Therefore, we select PCET as the dependent variable in the benefits model. The formula is as follows:

$$
\mathrm{PCET}=\beta_{0}+\beta_{1} \mathrm{YEAR06}+\beta_{2} \mathrm{GDP}+\beta_{3} \mathrm{GDP}_{\mathrm{R}}+\beta_{4} \mathrm{LIFA}+\beta_{5} \mathrm{LFDI}+\mu_{i}+\varepsilon_{i t}
$$

From Table 1, it can be seen that the coefficient of YEAR06 is positive and it has a significance level of 5\%. PECT has improved since the implementation of the industrial transformation policy, which indicates that there is a positive correlation between enterprise benefits and the promotion of industrial policies.

The coefficient of the GDP_R is negative but is not significant at the level of $10 \%$, indicating that it has little relationship with the growth of PECT, which probably lies in the gradual maturity of the enterprise production (and other reasons) while its correlation with the regional GDP is weak.

The coefficient of LFDI is positive, being significant at the level of $5 \%$, which shows that foreign direct investment and industrial enterprise efficiency are positively correlated. To some extent, it indicates that the autonomy of industrial enterprises in Dongguan is poor and that their dependence on export-oriented economy remains high.

The coefficient of LIFA is negative, being significant at the level of $10 \%$, indicating that business efficiency reduces as the fixed-asset investment of society increases, which may be due to the lag of fixed-asset investment, meaning that a large amount of capital investment results in reduced profits. Another possibility may be that the government mainly assisted small- and medium-sized enterprises, which in recent years are not included in the range of PCET's enterprises.

\section{Availability evaluation of industrial upgrade policies of the Pearl River Delta}

Based on our research into the policy evaluation of the industrial transformation and upgrade of Dongguan, this paper chooses other eight cities of the Pearl River Delta as the control group. Those cities are strongly similar to Dongguan in terms of location characteristics, development stage, and growth pattern, so we can explore the status of industrial transformation of those eight cities and make a comparison with that of Dongguan.

We can see from Table 2, that different from Dongguan, the government-led industrial transformation in the Pearl River Delta does not have a positive enough effect in terms of direction and effectiveness, while the market-led one had an improved impact. The whole society's fixed-asset investment makes the efficiency of industrial transformation in the Pearl River Delta increase but reduces it for Dongguan. This may be because in the process of industrial restructuring, the Pearl River Delta focused on improving the second industry investment, the independent $R$ \& D capability, and the product added-value of the second industry. While Dongguan was dedicated to the introduction of investment and to the vigorous development of the third industry (such as modern logistics, e-commerce, exhibition services, cultural and creative services, and other service industries). Whether it is in the Pearl River Delta or in Dongguan, the data reveal that the slowdown of the second industry is caused by a slowdown in GDP growth. The fixed-asset investment of society can make 
Table 2 The comparison between Dongguan and the Pearl River Delta

\begin{tabular}{|c|c|c|c|c|}
\hline \multirow[t]{2}{*}{ Variables } & \multicolumn{2}{|l|}{ Orientation model } & \multicolumn{2}{|l|}{ Benefit model } \\
\hline & Treatment group & Control group & Treatment group & Control group \\
\hline \multirow[t]{2}{*}{ Year06 } & 0.4127789 & 0.0650052 & 7.021549 & -4.857668 \\
\hline & $(0.014)$ & $(0.813)$ & $(0.050)$ & $(0.210)$ \\
\hline \multirow[t]{2}{*}{ GDP } & -0.0003815 & -0.0000692 & & \\
\hline & $(0.002)$ & $(0.072)$ & & \\
\hline \multirow[t]{2}{*}{ GDP_R } & 0.0391718 & -1.964066 & -0.1042196 & 8.761576 \\
\hline & $(0.000)$ & $(0.090)$ & $(0.523)$ & $(0.522)$ \\
\hline \multirow[t]{2}{*}{ ThirdZ } & $-6.79 \mathrm{E}-08$ & $2.06 \mathrm{E}-08$ & & \\
\hline & $(0.185)$ & $(0.303)$ & & \\
\hline \multirow[t]{2}{*}{ FDI } & 0.00000213 & $-2.43 \mathrm{E}-07$ & & \\
\hline & $(0.075)$ & $(0.751)$ & & \\
\hline \multirow[t]{2}{*}{ LFDI } & & & 16.03161 & 45.54966 \\
\hline & & & $(0.026)$ & $(0.000)$ \\
\hline \multirow[t]{2}{*}{ LIFA } & 0.2318513 & 1.121248 & -6.936575 & 15.6962 \\
\hline & $(0.006)$ & $(0.048)$ & $(0.070)$ & $(0.000)$ \\
\hline \multirow[t]{2}{*}{ _cons } & -0.782132 & -6.793038 & -141.1331 & -745.2396 \\
\hline & $(0.041)$ & $(0.137)$ & $(0.036)$ & $(0.000)$ \\
\hline
\end{tabular}

the relative growth rate of the second industry increase quickly, and the increase of foreign direct investment improves the efficiency of industrial transformation.

\section{Conclusions}

Comprehensive analysis shows the following: (1) Since 2006, the Dongguan municipal government-led industrial transformation has achieved certain effectiveness. In the support of various policies, the efficiency of industrial enterprises increased. However, the direction of the industrial upgrading is not significant. In contrast, industrial restructuring of the Pearl River Delta relied more on market-driven industrial transformation; (2) The slowdown of the relative speed of development of the second industry is likely to be the inevitable result of GDP growth, rather than government policy; (3) Whether it is in the Pearl River Delta or in Dongguan, the level of opening up can promote not only the development of the second industry but also industrial upgrading, which shows the Pearl River Delta still relies highly on foreign capital and technology to promote industrial restructuring. (4) Fixed-asset investment of society increased the industrial transformation benefit of the Pearl River Delta. But for Dongguan, the whole social fixed-asset investment accelerated the relative development of the second industry and decreased the efficiency of industrial transformation. The results from our analysis reveal that government-led industrial policy plays a role in the upgrading of industrial structure, but knowledge of its effectiveness will be further advanced with investigations that combine different policy objectives and the specific area, with the indispensable consideration of the important effect of market mechanisms on industrial transformation. 
Economics Major Research Task of Fostering Project; and the Fundamental Research Funds for the Central Universities (14ZZD006) (NKZXA1406).

\section{Authors' contributions}

ZW conceived the framework and ideas of the entire study and wrote the first and last main sections of this article. XX wrote the second and third main section. ZL wrote the fourth section. All authors read and approved the final manuscript.

\section{Authors' information}

Zhifeng Wang is professor and doctoral supervisor of the School of Management Science and Engineering at Central University of Finance and Economics. His research areas include urban economy, public policy, and regional economics. He has been in charge of many national-level research projects.

Xiaoming Xu and Zhiqing Liang are master students of the School of Management Science and Engineering at Central University of Finance and Economics. Their research areas include urban economy and regional economics.

\section{Competing interests}

The authors declare that they have no competing interests.

Received: 8 September 2016 Accepted: 8 November 2016

Published online: 15 November 2016

\section{References}

Hanxian W (2011) Study on the role of government in the industries transformation in Guangdong province.

Dissertation Doctoral of South China University of Technology

Ito T (1991) The Japanese Economy. The Japanese Economy, vol 1. The MIT Press

Liew M, White LB (2007) Concurrent Temporal Planning Using Timed Petri Nets - Policy Evaluation. Australian Joint Conference on Advances in Artificial Intelligence 4830: 727-731. Springer-Verlag

Lingling Z (2011) Study on the industrial transformation of the Pearl River Delta. Academic Research Journal 8:71-75 Lingxiang K (2014) Research on the industrial policy of China's local government and local industrial transformation. Dissertation Doctoral of Capital University of Economics and Business

Tybout JR (1992) Linking trade and productivity: new research directions. World Bank Econ Rev 6(2):189-211.

Weigen D, Ran W (2010) The relation between harnessing the global value chain and the transition of the export-type economic industries. Academic Research Journal 1:56-62

Weinian Q, Xiuxian T (2011) Research on the industry transformation and upgrading path in Dongguan city. Economic Research Guide 23:85-86

Wenfeng L (2007) Institutional analysis of Taiwan-funded enterprises in Dongguan. Zhujiang Economy 194(10):19-26.

Xiaofeng W (2007) Study on the transformation of economic development stages and patterns in Dongguan. The era of economic and Trade Affairs. 1Z:76-77

Zhiyong W, Xuemei C (2014) Policy availability of the industrial upgrade. Urban Development Studies 21(9):69-76

\section{Submit your manuscript to a SpringerOpen ${ }^{\circ}$} journal and benefit from:

- Convenient online submission

- Rigorous peer review

- Immediate publication on acceptance

- Open access: articles freely available online

- High visibility within the field

Retaining the copyright to your article 